\title{
LA TRADUCCIÓN DE AJUAR FUNERARIO DE FERNANDO IWASAKI: UN ESTUDIO DE CASO DE DOS MICRORRELATOS FANTÁSTICOS DE TERROR
}

\author{
THE TRANSLATION OF FERNANDO IWASAKI'S AJUAR FUNERARIO: A CASE \\ STUDY OF TWO FANTASTIC SHORT-SHORT STORIES OF TERROR
}

Ellen LAMBRECHTS

KU Leuven (Bélgica)

ellen.lambrechts@kuleuven.be

\begin{abstract}
Resumen: Según Andres-Suárez, estamos en la «era de la brevedad». En lo que se refiere a la literatura, observamos que cuanto más se reducen los relatos, tanto más significado cobran sus palabras. En efecto, la colección Ajuar funerario (2004) del escritor peruano Fernando Iwasaki (Lima, 1961) contiene cien relatos hipercortos, casi todos dotados de un significado fantástico que el lector no alcanza a discernir con certidumbre y que, por eso, le da terror. El presente artículo se consagra al análisis de «El dominio» $\mathrm{y}$ «No hay que hablar con extraños», dos microrrelatos en los que dicha dimensión fantástica no solamente emana de los temas abordados, como en las manifestaciones tradicionales del género, sino también, y sobre todo, de la manera en que estos temas son introducidos en la narración. Al comparar los relatos con sus versiones inglesas, encontramos que las traducciones se conforman a las normas del sistema literario receptor, desambiguando las enunciaciones narrativas y, por consiguiente, despojando las historias de su halo fantástico-terrorífico.
\end{abstract}

Palabras clave: lo fantástico; terror; traducción; Fernando Iwasaki.

Abstract: According to Andres-Suárez, we live in the «era of brevity». As far as literature is concerned, we observe that the shorter stories are, the more significance their words gain. Indeed, the volume Ajuar funerario (2004), written by the Peruvian author Fernando Iwasaki (Lima, 1961), contains eighty-nine short-short stories and almost all of them have a fantastic meaning which the reader is unable to discern with certainty and which, therefore, strikes terror into him. The present article undertakes the analysis of «El dominio» and «No hay que hablar con extraños», two short-short stories which open up a fantastic dimension that renews the traditions of the genre by focusing not only on thematic elements, but also, and above all, on the way these are introduced in the narration. 
104 | Tropelías. Revista de Teoría de la Literatura y Literatura Comparada, 32 (2019) Ellen Lambrechts

As we compare the stories with their English versions, we find that the translations conform to the norms of the target literary system, disambiguating the narrative enunciations and, consequently, taking away the fantastic and the terror from them.

Keywords: fantastic narrative; terror; translation; Fernando Iwasaki. 


\section{$\mathbf{I}$}

\section{ntroducción}

Desde la década de los sesenta, la literatura hispanoamericana está entrando en la «era de la brevedad» (Andres-Suárez, 2010: 158). Inscribiéndose en esta tendencia, la colección de microrrelatos Ajuar funerario (2004) del escritor peruano Fernando Iwasaki ${ }^{1}$ (Lima, 1961) se caracteriza por su agudeza y concisión. Este estudio se propone ilustrar cómo Iwasaki explota el microrrelato para configurar un ámbito fantástico de terror. A este respecto, resultan ilustrativos los microrrelatos «El dominio» y «No hay que hablar con extraños»: combinan temas fantásticos tradicionales, como el diablo y el fantasma, con manipulaciones del lenguaje típicas de lo fantástico postmoderno, como la literalización del sentido figurado, induciendo terror en el lector. Esto quiere decir que los textos que serán nuestro objeto de estudio se encuentran entre lo fantástico tradicional y lo fantástico contemporáneo o, para utilizar los términos de Mery Erdal Jordan, entre lo «fantástico de percepción» y lo «fantástico de lenguaje» (1998: 34).

Puesto que en los microrrelatos la manera de contar es tan y hasta más importante que la historia misma, resulta interesante averiguar qué ocurre con las narrativas de «El dominio» $\mathrm{y}$ «No hay que hablar con extraños» - y con su dimensión fantástica - cuando se realizan en otra lengua. A este efecto, compararemos la versión original de Ajuar funerario con sus primeras traducciones al inglés ${ }^{2}$.

\section{La relación entre el microrrelato, lo fantástico y el terror}

Según indica su contraportada, «Ajuar funerario es un homenaje a la literatura de terror y a la micronarrativa». Efectivamente, la colección consta de cien microrrelatos que causan todos, en mayor o menor medida, el terror en el lector. Como cada uno de los microrrelatos se orienta hacia el mismo efecto, Ajuar funerario responde a la llamada «unidad de efecto» (Poe, 1979: 442). Esta unidad, de la que Edgar Allan Poe habla ya en $1842^{3}$, se logra cuando «in the whole composition there [is] no word written of which the tendency, direct or indirect, is not to the one pre-established design» ${ }^{4}(1979: 446)$. A este respecto, «El dominio» $\mathrm{y}$ «No hay que hablar con extraños» permiten ilustrar cuánto más importante resulta esta «unidad de efecto» en el caso del microrrelato que, por su breve extensión, no

\footnotetext{
${ }^{1}$ También Tres noches de corbata (1987), A Troya, Helena (1993), Inquisiciones Peruanas (1994), Un milagro informal (2003), Helarte de amar (2006), España, aparta de mí estos premios (2009), Papel Carbón (2012c), Es difícil hacer el amor (humor) pero se aprende (2014a) y El atelier de Vercingétorix (2017) se presentan como colecciones de ficciones breves.

${ }^{2}$ La primera traducción de «El dominio» $\mathrm{y}$ «No hay que hablar con extraños» fue efectuada en 2012 por Megan Berkobien y publicada en el segundo número de la revista que ella misma fundó, Canon Translation Review. Posteriormente, en 2014, Steven J. Stewart tradujo toda la colección de microrrelatos y la publicó bajo el título Grave Goods (Blood Bound Books, USA, 2014b). Visto el marco limitado del estudio, nos ceñiremos al análisis de las primeras traducciones.

${ }^{3} 1842$ es el año en el que Graham's Magazine publica la reseña que hizo Edgar Allan Poe de la colección de relatos TwiceTold Tales de Nathaniel Hawthorne.

${ }^{4}$ «No debería haber una sola palabra en toda la composición cuya tendencia, directa o indirecta, no se aplicara al designio preestablecido» (Zavala, 1993: 17).
} 
admite palabras superfluas: como analizaremos a continuación, los citados microrrelatos solo seleccionan las palabras que contribuyen, de una u otra manera, a crear un efecto fantástico.

Tal efecto tiende a producir en el lector un «miedo metafísico», para utilizar la terminología de David Roas (2011: 95) o un «terror fantástico», para decirlo con las palabras de Elton Honores (2014: 43). Por «miedo metafísico», Roas entiende «esa reacción, experimentada tanto por los personajes [...] como por el lector, ante la posibilidad efectiva de lo sobrenatural, ante la idea de que lo irreal pueda irrumpir en lo real (y todo lo que eso significa)» (2001: 30). Honores coincide con Roas cuando afirma que «el miedo supone el momento previo a la presencia concreta y fáctica del "hecho" (comúnmente sobrenatural y asociado comúnmente a lo monstruoso, para los casos del terror "fantástico") que altera el orden natural», pero destaca que «se manifiesta en el plano de la mente» (2014: 43). Esto significa que el miedo o el terror son puramente psicológicos, al igual que la vacilación inherente a lo fantástico. Más específicamente, el miedo o el terror deriva de la vacilación: al ver anulada su capacidad para captar y dominar — con la mente - la realidad, el protagonista y/o el lector sentirá(n) un miedo metafísico o terror fantástico.

En cuanto a la vacilación, afirmamos, citando a José Luis Fernández Pérez, que «en razón de su brevedad, o más bien, de su reducida escala de representación, los microcuentos presentan una serie de ambigüedades discursivas que enriquecen las posibilidades de lectura» (2010: 129). En consecuencia, el microrrelato se acerca al relato fantástico: «propende a que el lector vacile y fluctúe en los espacios de incertidumbre» (2010: 130). Este estado de incertidumbre está, en el presente caso, asociado a lo fantástico, porque el lector no sabe decidir si lo narrado pertenece a la realidad tal cual la conoce, o a otra realidad, oculta para él hasta entonces.

El microrrelato y el relato fantástico no solo son afines porque sumergen al lector en esta ambigüedad interpretativa, sino además porque lo exponen a los así llamados «desafíos del silencio» (Campra, 2008: 107-138). En efecto, el microrrelato prescinde de descripciones de personajes, de referencias espacio-temporales, pero también de explicaciones imprescindibles para entender cómo lo narrado — aparentemente anormal — debe ser interpretado. De esta forma, el microrrelato ilustra particularmente bien la teoría de Rosalba Campra sobre la literatura fantástica, según la cual los vacíos en el texto «sugiere[n] la presencia de vacíos en la trama de la realidad» (2008: 112). Por ser tan llamativos, estos vacíos aterrizan mucho más al lector que la posible presencia del diablo o de un fantasma.

La presente inclinación del microrrelato por lo fantástico es observable tanto en la modalidad de percepción como en la modalidad de lenguaje. Esto se debe a que en ambas modalidades lo fantástico es «[una] de las vías más productivas para ahorrar espacio textual» (Andres-Suárez, 2010: 104) e, inversamente, a que «la brevedad - y la tensión inherente a ésta- parece potenciar el efecto trasgresor» inherente a lo fantástico (Casas, 2008: 138). Tzvetan Todorov parte de la idea de que «sans ‘événements étranges', le fantastique ne peut même pas apparaître» (1970: 98). Tanto «El dominio» como «No hay que hablar con extraños» responden a esta idea tradicional del género fantástico y enfrentan al lector con un evento extraño. Iwasaki va así a contracorriente: mientras que el género 
fantástico se manifiesta, a partir de la segunda mitad del siglo XX, cada vez menos en el nivel del contenido (y cada vez más en el nivel discursivo), él sigue recurriendo a los temas fantásticos tradicionales. Por tanto, no debe sorprendernos que la contraportada de Ajuar funerario plantee la pregunta siguiente: «¿Es posible que los fantasmas, las pesadillas, los ritos y las supersticiones nos puedan seguir asustando en pleno siglo XXI?». Nuestra respuesta es la siguiente: sí, es posible, gracias a la actualización de estos temas. Raquel Velázquez ya ha señalado que «los relatos recogidos en Ajuar funerario ofrecen una nueva mirada sobre aquellos motivos o personajes propios de la tradición clásica de la literatura fantástica» (2012: 182-183), pero nosotros intentaremos desentrañar qué papel desempeña el lenguaje en esta renovación y cuáles son sus implicaciones para la traducción. Como lo percibe con acierto Ana Casas, «en este tipo de textos [= los microrrelatos] la trasgresión fantástica muchas veces se equipara a la trasgresión del lenguaje» (2008: 150). En efecto, si bien la forma corta de los textos no deja de influir en la manera en que sus temas son tratados, el impacto se da principalmente a nivel del lenguaje:

Es precisamente en la modalidad de lenguaje donde el microrrelato extrema las posibilidades expresivas de lo fantástico: cuanto menor es el espacio del que se dispone, mayor significación adquiere cada una de las palabras que aparecen en la obra. O dicho de otro modo: una mínima modificación, alteración o cambio a nivel verbal, una mínima violación de la doxa lingüística, puede provocar la irrupción de lo imposible (Casas, 2010: 11).

A continuación, nos detendremos en uno de los experimentos lingüísticos que más marcan los microrrelatos de Ajuar funerario en general y «El dominio» $\mathrm{y}$ «No hay que hablar con extraños» en particular: el juego con el sentido literal y el sentido figurado ${ }^{5}$.

\section{La literalización del sentido figurado}

\section{1. «El dominio»}

«El dominio» empieza cuando el protagonista constata que el nombre de dominio www.infierno.com, que identifica al sitio web correspondiente, todavía no está registrado: él mismo lo compra y lo revende luego por mucho dinero. Tanto mayor es la sorpresa al descubrir poco después que www.infierno.com está de nuevo disponible. En la esperanza de ganar otra vez mucho dinero, vuelve a solicitarlo. Hasta aquí, el relato puede ser calificado tal vez de extraño, pero no de fantástico. Lo fantástico solo irrumpe al final, cuando el protagonista, y el lector con él, leen la respuesta a su solicitud: «"Estimado cliente, de acuerdo con nuestros archivos su alma ya forma parte de nuestra base de datos. Reciba un cordial saludo". El nombre del remitente era inverosímil» (Iwasaki, 2012a: 109). A este respecto, la palabra «inverosímil» es muy significativa: la posibilidad de que el diablo sea el remitente es, en efecto, poco verosímil, sobre todo teniendo en cuenta que la compra y venta del dominio del infierno son, en sí, «posibles según lo verosímil» (Reisz, 2001: 213). En este sentido, la posible aparición del diablo conlleva lo que Susana Reisz denomina una «desverosimilización

\footnotetext{
${ }^{5}$ Para más sobre la relación entre lo fantástico y el lenguaje en general y este recurso en particular, véase el cuarto capítulo de Roas (2011) y el séptimo capítulo de Campra (2008).
} 
retrospectiva»: lo que primero parece verosímil, se desverosimiliza después (2001: 213). Efectivamente, es solo cuando resulta que el protagonista no ha vendido el dominio del infierno, sino su propia alma, que «El dominio» se hace inverosímil. Gracias a la polisemia de la palabra, «dominio» puede ser interpretado no solo como dominio virtual — www.infierno.com - sino también como dominio real —el poder del diablo_- Es esta última interpretación la que abre paso a lo fantástico, por una parte a lo fantástico de percepción — visto el tema del diablo — pero por otra parte a lo fantástico de lenguaje — dado que el tema del diablo es introducido por medio de un juego con el lenguajeEste juego con el lenguaje consiste en la literalización del sentido figurado, porque pasamos del sentido figurado, o virtual en este caso, al sentido literal de la palabra «dominio». Como modalidad de lo fantástico, la literalización del sentido figurado permite «la imposición de la realidad lingüística sobre la realidad empírica representada en el texto» (Rodríguez Hernández, 2010: 6). Así, «El dominio» logra imponer lo fantástico de lenguaje sobre lo fantástico de percepción.

Con este juego lingüístico el microrrelato consigue además trasladar al lector el terror del protagonista que, construido sobre el «tópico del terror» de «la figura del diablo» ${ }^{6}$ (Honores, 2014: 133-139), cabe dentro de la tradición sobre el demonio «proveniente del discurso literario, cuya presencia supondrá para los protagonistas, terror y espanto, por representar la encarnación del mal» (2014: 135). El protagonista de «El dominio» se horroriza al leer el nombre del remitente «inverosímil», pero no comunica este nombre al lector. El lector se espanta, por su parte, al estar solo parcialmente informado. Como solo puede adivinar quién envió el mensaje, está y quedará en la incertidumbre. Esta incertidumbre - la del lector - es, como mínimo, tan aterradora como la del protagonista, este al menos sabe qué es lo que le hace incierto. Si bien es verdad que la (posible) presencia de una figura tan maléfica como el diablo infunde terror, el protagonista siempre puede intentar exorcizarlo o deshacer la venta de su alma. El lector, en cambio, no puede hacer más que aceptar que nunca sabrá a ciencia cierta quién firmó el mensaje, y menos quién lo escribió realmente. A este respecto, el final abierto es muy efectivo: hace que la vacilación del lector se mantenga más allá del microrrelato.

\section{2. «No hay que hablar con extraños»}

«No hay que hablar con extraños» se presenta como el relato realista de una niña traviesa que, a pesar de los consejos de su mamá, establece contacto con Agustín, un completo extraño. Solo toma un giro inesperado al final, cuando se pone en claro cómo el lector debe interpretar las palabras «seguro que [mamá] no me vuelve a ver»:

\footnotetext{
${ }^{6}$ Este tópico vuelve también en otros microrrelatos de Ajuar funerario: «666», por ejemplo, introduce el tema del diablo de forma similar a «El dominio» con la diferencia de que el protagonista de aquel microrrelato no recibe un correo electrónico de un remitente cuyo nombre era inverosímil, sino una llamada telefónica de «un número inverosímil» (2012a: 90); microrrelatos como «Antigüedades» o «La soberbia», en cambio, hacen suponer que el propio narrador-protagonista es el diablo al asociarlo con el infierno.
} 
NO HAY QUE HABLAR CON EXTRAÑOS Así me decía siempre mamá, pero Agustín no era un extraño porque todos los días me ofrecía caramelos a la salida del colegio. Además, cada vez que me llevaba a su taller me regalaba muñecas. [...] Mamá es una miedosa porque dice que si hablo con extraños seguro que no me vuelve a ver. [...] A veces salgo del taller de Agustín y vuelvo al colegio porque ahora nadie me llama la atención. Me gusta hacer lo que quiero y caminar de noche, pero me da pena mamá, siempre mirando triste por la ventana. Le hablo y no me hace caso y entonces vuelvo al taller con mis juguetes de niebla. Seguro que si Agustín no fuera un extraño mamá me volvería a ver (2012a: 44-45; cursivas nuestras).

En el contexto del relato, la interpretación conveniente de «la madre no vuelve a ver a su hija» parece ser que la hija está secuestrada o incluso asesinada por Agustín. Sin embargo, el relato apunta a una interpretación más literal: la madre ya no puede ver a su hija porque esta se ha hecho invisible. Es decir, la hija se ha convertido en un fantasma, que todavía está presente, pero ya no de manera perceptible. Cabe señalar que el relato no sugiere en ninguna ocasión esta interpretación fantástica, así que es el lector el que debe realizarla. Al revés, es también posible que el lector no la realice, y que suponga que la niña — lejos de su mamá, encerrada en el taller de Agustín — se imagina a su mamá sola, por lo cual entabla una conversación imaginaria con ella.

En el caso de que la niña-narradora esté muerta, la narración puede ser calificada de «innatural», dado que narrar póstumamente es física y lógicamente imposible (Alber, 2009: 80). Como si fuera una muerta con vida, la niña narra su historia, expresa sus sentimientos, vaga por su colegio, su casa... Confrontando al lector con una narradora-fantasma, «No hay que hablar con extraños» «invites us [= al lector] to stretch our cognitive categories to picture a situation in which the dead narrator continues to interact with the world she had to leave», así que puede ser explicado «in terms of our inability to envision death as the definite end of our existence, or in terms of the wishes of the bereaved that the dead somehow continue to exist» (2009: 90).

No es casual que esta niña-fantasma aparezca de noche: el marco nocturno crea un terror ambiental que prepara al lector para el terror fantástico que sigue. Concretamente, el miedo es el resultado de un hábil manejo del tópico narrativo de «la joven mujer muerta» ${ }^{7}$, es decir, Iwasaki conecta el terror fantástico con «el terror a lo sexual» (Honores, 2014: 114-115). Tal como lo indica Honores, «en el relato de terror, la transgresión de lo moral aceptado — en relación a lo sexualenmarca la irrupción de lo fantástico» (2014: 115). En «No hay que hablar con extraños», la transgresión sexual se da cuando la niña dice que «Con Agustín yo juego a que me toca y yo lo toco, y siempre gano pues al final no se puede aguantar», además de que «En el taller de Agustín hay muchas cosas que cortan y queman y pinchan» (2012a: 44). La niña es, sin embargo, puro candor. Por una parte, esta candidez induce terror en el lector, porque el lector sí cala las verdaderas intenciones de Agustín. Por otra parte, lo hace reír: el contraste entre lo que ocurre y lo que la niña piensa que ocurre es tan grande que resulta humorístico.

\footnotetext{
${ }^{7}$ En varios de los microrrelatos recogidos en Ajuar funerario aparece una mujer muerta. Algunos exigen, al igual que «No hay que hablar con extraños», la participación del lector para la aparición del fantasma. Dentro de este grupo se incluyen, entre otros, «Aire de familia», que solo habla de una «niña que viene por las noches» (2012a: 100) o «Pesadilla», que trata de una niña que viene siempre de noche en los sueños del narrador-protagonista, pero que al final también lo visita de improviso cuando está aún despierto. Otros, como «Aullidos» o «La chica del auto stop, I» abordan el tópico de la mujer muerta explícitamente, por lo que no necesitan la participación plena del lector.
} 


\section{3. «El dominio» $\mathbf{y}$ «No hay que hablar con extraños» en inglés}

\section{1. «The Domain»}

Como hemos explicado en el apartado 2.1, en «El dominio» la palabra «dominio» se refiere al sentido figurado (virtual), al principio, y al sentido literal, al final, sin que el microrrelato señale este desplazamiento de sentido. El lector vacilará, por lo tanto, en atribuir un sentido estable y unívoco al microrrelato. En «The Domain» - la traducción inglesa de «El dominio» efectuada por Megan Berkobien ${ }^{8}$ _, en cambio, la traductora explicita cómo el lector debe interpretar la palabra «domain», es decir, traduce «el dominio www.infierno.com no estaba registrado» (2012a: 108) por «the domain name www.infierno.com was unregistered» (Iwasaki, 2012b; cursivas nuestras) y destaca que el «domain» del que el narrador-protagonista está hablando es el «web address» (2012b; cursivas nuestras). De la añadidura de las palabras «name» $\mathrm{y}$ «web», el lector puede deducir que el sentido inicial de «domain» es nombre de dominio. También el sentido final de «domain» es ya mencionado por la traductora: a mitad del microrrelato, traduce el grupo de palabras «dominio del infierno» (2012a: $108,109)$ por «infernal dominion» $(2012 b)$ y no por el equivalente «infernal domain» ${ }^{9}$. Sustituyendo la palabra polisémica original por una palabra monosémica, desambigua el microrrelato. De ahí que el lector de la traducción, a diferencia del lector del original, ya se haya formado una idea de los dos sentidos posibles de «domain» cuando irrumpe lo fantástico. Por consiguiente, no se sentirá tan aterrado.

El terror se pierde también por la alteración de los tiempos verbales. Esta alteración se debe sobre todo a que Berkobien utiliza — en la frase clave del microrrelato — un presente donde Iwasaki usa un pasado, pero también a otras confusiones.

Al final del microrrelato, «El dominio» cambia al pasado, mientras que «The Domain» cambia al presente: «El nombre del remitente era inverosímil» (2012a: 109; cursivas nuestras) se traduce por «The sender's name seems far-fetched» (2012b; cursivas nuestras). Es, de hecho, una doble modificación: el imperfecto es reemplazado por un presente y el verbo «ser» por el verbo inglés «to seem» en vez de por «to be». En cuanto a «El dominio», el imperfecto se utiliza para «expresar situaciones que sólo tienen validez en el tiempo en que ocurrieron los eventos narrados, pero no así en el momento de la narración» (Lubbers Quesada, 2005: 166). Esto implica que «el nombre del remitente era inverosímil» para el personaje de entonces, pero ya no necesariamente para el narrador actual. A causa de este desdoblamiento entre el personaje y el narrador, el lector de «El dominio» ignora si el nombre sigue siendo inverosímil en el momento de la narración, o si entretanto ya ha recibido alguna

\footnotetext{
${ }^{8}$ Como se trata de una publicación digital, carece de paginación. Por eso, citaremos la traducción de Megan Berkobien solo mediante el año de publicación.

9 Conforme a la definición del Diccionario de la lengua española, la palabra «dominio» se refiere o bien a una «denominación que identifica a un sitio en la red y que indica su pertenencia a una categoría determinada» o bien al «poder o ascendiente que se ejerce sobre otra u otras personas» (Real Academia Española, 2014: «dominio»). Asimismo, la palabra inglesa «domain» denota «a set of websites on the internet that end with the same letters, for example .com» o «an area of interest or an area over which a person has control» (Cambridge University Press, 2017: «domain»). La

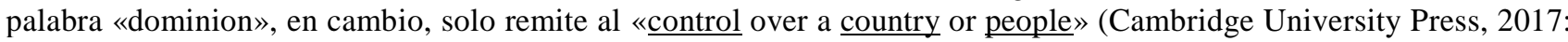
«dominion»).
} 
explicación verosímil. El lector de «The Domain», en cambio, sabe que «the sender's name seems farfetched» en la actualidad. Gracias al uso del presente, el lector conoce el juicio actual del narrador. No obstante, esto va en detrimento del efecto fantástico: cuanto más sabe el lector, menos vacilará. Además, la opción por otro verbo copulativo — «to seem» en vez de «to be» como equivalente de «ser»— reduce el poder terrorífico de la frase. Esto se explica por el hecho de que «ser» denota algo real y «to seem» algo imaginario: es mucho más aterrador verse confrontado con un remitente que es realmente inverosímil que con un remitente que solo da esta impresión.

\section{2. «You Shouldn't Talk to Strangers»}

Como ya indicamos, la narradora de «No hay que hablar con extraños» es una niña. Esto se deduce del punto de vista adoptado, pero también del estilo asumido. En la primera traducción inglesa del microrrelato, realizada por Megan Berkobien, el estilo infantil característico de «No hay que hablar con extraños» se pierde parcialmente. Esto se debe, en primer lugar, al lenguaje utilizado por Berkobien. Si Iwasaki utiliza palabras y expresiones sencillas para dejar claro que provienen de una niña, Berkobien las traduce por construcciones más elocuentes. Este procedimiento se aplica, por ejemplo, a la descripción del avión de Agustín. Según la niña, el avión sirve «para volar e irnos de viaje» (2012a: 44) o, para decirlo en inglés, «to fly away on vacation» (2012b). Ambas descripciones - la española y la inglesa - significan lo mismo, pero no funcionan igual. Al sustituir el estilo infantil por un estilo más elegante, la versión inglesa no alcanza el efecto humorístico de la versión española.

El estilo muy típico de la niña se pierde también cuando una frase informal como «Muy bueno era Agustín, me hacía cariñitos» (2012a: 44) es traducida formalmente por «Agustin was really nice, always smothering me in cuddles» (2012b). Además de pertenecer a un registro más formal, «smothering me in cuddles» no reproduce el diminutivo de «me hacía cariñitos». Por consiguiente, no transmite el matiz afectivo del original ${ }^{10}$. Como la traducción no expresa el afecto que la niña le ha cobrado a Agustín, es estilísticamente más neutra. Sin embargo, una traducción más formal no siempre es más neutral, como muestra la traducción de «Me gusta hacer lo que quiero» (2012a: 45) por «I like doing as I please» (2012b). Esta traducción sorprende porque es tan formal, a pesar de que sale de la boca de una niña. Una traducción más coloquial — más adaptada al estilo de la niña— hubiera sido «I like doing what I want (to do)». A la inversa, una palabra como «miedosa» (2012a: 44) pasa de un registro neutro-formal a un registro informal al ser traducida como «worrywart» (2012b). Resulta asombroso que la traducción no opte por la palabra inglesa «coward», que hubiera permitido mantener no solo el registro, sino también el significado original, remitiendo a una medrosa y no a una pesimista como la palabra «worrywart».

No solo se ha modificado el estilo del microrrelato, sino también su significado. Concretamente, se notan dos alteraciones: la traducción de «me da pena mamá» (2012a: 45) por «it worries mama»

\footnotetext{
${ }^{10}$ En Traducir la voz ficticia, Jenny Brumme insiste en que el diminutivo no solo sirve para «indicar la reducción de tamaño», sino también para expresar «la implicación afectiva del narrador» (2012: 65).
} 
(2012b) y de «no me hace caso» (2012a: 45) por «she doesn't notice me» (2012b). Ambas modificaciones aparecen al final, por lo que tienen un gran impacto en la interpretación del microrrelato. En cuanto a la primera modificación, la traducción se centra en el estado emotivo de la madre y no en el de la niña. Sin embargo, es justamente aquí donde el original engaña al lector: describe las emociones (humanas) de la niña, pero sin especificar que la niña las vive en calidad de fantasma. Además, la traducción añade el pronombre «it», que refiere a la condición ambulante de la niña, sugiriendo la posibilidad de que la madre esté al tanto de que su hija vive una vida fantasmal. Así, la traducción interviene mucho más en la interpretación que el original.

También la segunda modificación facilita la interpretación del microrrelato: reemplaza un verbo vago por otro más preciso. Mientras que «[mamá] no me hace caso» (2012a: 45) no explicita que la madre ve o no ve a su hija — solo que no le presta atención — «she doesn’t notice me» (2012b) sí deja claro que la niña es invisible. Debido a esta alteración, y a la primera, "You Shouldn’t Talk to Strangers» invita al lector a una lectura fantástica, una lectura que solo está implícitamente presente en «No hay que hablar con extraños».

\section{Conclusiones}

El presente estudio ha intentado exponer cómo Fernando Iwasaki consigue crear un efecto fantástico de terror en «El dominio»y «No hay que hablar con extraños», revitalizando los temas fantásticos tradicionales con unos juegos postmodernos con el lenguaje propios de lo fantástico contemporáneo. Especialmente la literalización del sentido figurado cumple un papel primordial en el proceso de vacilación: abre una nueva realidad donde una intervención del diablo o transformación en fantasma no parece ser tan extraña.

En las traducciones elaboradas por Megan Berkobien, esta tergiversación de las palabras y de la realidad desaparece, por lo que el lector tiene menos dudas e incertidumbres. Debido a que la traductora tiende a añadir unas aclaraciones y a sustituir unas palabras o colocaciones por otras supuestamente iguales, no se pone en marcha el proceso de la literalización del sentido figurado y, por tanto, tampoco el efecto fantástico terrorífico de los microrrelatos originales.

«The Domain»y «You Shouldn’t Talk to Strangers» siguen aferrándose, pues, a lo fantástico de percepción, mientras que «El dominio» $\mathrm{y}$ «No hay que hablar con extraños» dan un giro a esta modalidad tradicional de lo fantástico, combinándola con lo fantástico de lenguaje. Más concretamente, las traducciones inglesas han sido adaptadas a las expectativas del lector del sistema literario inglés, tan familiarizado con lo fantástico tradicional, de modo que resultan reconocibles y «aceptables» (Toury, 1978: 88-89). En consecuencia, inducen en menor medida la vacilación y el terror que de ella se deriva, ofreciendo un asidero al lector donde los originales lo desconciertan ${ }^{11}$.

\footnotetext{
${ }^{11}$ Sería interesante averiguar si se saca una conclusión análoga de las traducciones posteriores de «El dominio» y «No hay que hablar con extraños» realizadas por Steven Stewart, porque esto permitiría calibrar los resultados obtenidos en este estudio de caso.
} 
La traducción de Ajuar funerario de Fernando Iwasaki: un estudio de caso...

\section{Referencias bibliográficas}

AlBER, J. (2009): «Impossible Storyworlds-and What to Do with Them», Storyworlds: A Journal of Narrative Studies, núm. 1, pp. 79-96.

ANDRES-SUÁREZ, I. (2010): «El microrrelato: caracterización y limitación del género», en D. RoAS, ed., Poéticas del microrrelato. Madrid, Arco Libros, pp. 155-179.

BRUMME, J. (2012): Traducir la voz ficticia. Berlín, De Gruyter.

Cambridge University Press (2017): Cambridge Dictionary. Cambridge, Cambridge University Press.

CAMPRA, R. (2008): Territorios de la ficción. Lo fantástico. Sevilla, Renacimiento.

CASAS, A. (2008): «Lo fantástico en el microrrelato español (1980-2006)», en I. ANDRES-SUÁREZ y A. RIVAS, eds., La era de la brevedad: el microrrelato hispánico. Palencia, Menoscuarto Ediciones, pp. 137-157.

- (2010): «Transgresión lingüística y microrrelato fantástico», Ínsula. Revista de letras y ciencias humanas, núm. 765, pp. 10-13.

ERDAL JORDAN, M: (1998). La narrativa fantástica. Evolución del género y su relación con las concepciones del lenguaje. Frankfurt/Madrid, Vervuert/Iberoamericana.

FÉRNANDEZ PÉREZ, J. L. (2010): «Hacia la conformación de una matriz genérica para el microcuento hispanoamericano», en D. RoAS, ed., Poéticas del microrrelato. Madrid, Arco Libros, pp. 121153.

HONORES, E. (2014): La civilización del horror. El relato de terror en el Perú. Lima, Editorial Agalma. IWASAKI, F. (1987): Tres noches de corbata. Lima, Ediciones Ave. (1993): A Troya, Helena. Bilbao, Instituto Vasco de las Artes y las Letras. (1994): Inquisiciones peruanas. Sevilla, Padilla Libros.

_ (2003): Un milagro informal. Madrid, Alfaguara.

- (2006): Helarte de amar. Madrid, Páginas de Espuma.

— (2009): España, aparta de mí estos premios. Madrid, Páginas de Espuma.

— [2004] (2012a): Ajuar funerario. Madrid, Páginas de Espuma. (2012b): «From Grave Goods: Fernando Iwasaki» (Trad. M. Berkobien). Canon Translation Review, 2. Recuperado de http://canontranslationreview.com/2012/09/23/from-grave-goodsfernando-iwasaki-megan-berkobien-translator/.

(2012c): Papel carbón. Madrid, Páginas de Espuma.

- (2014a): Es difícil hacer el amor (humor) pero se aprende. Santiago de Cuba, Editorial Oriente. (2014b): Grave Goods. Trad. S. Stewart. USA, Blood Bound Books.

- (2017): El atelier de Vercingétorix. San José, Editorial Germinal.

LUBbers QueSADA, M. (2005): «Perspectivas aspectuales del presente y del imperfecto en español», en M. Lubbers Quesada y R. MALdONAdo, eds., Dimensiones del aspecto en español. México, Universidad Nacional Autónoma de México, pp. 149-171. 
114 | Tropelías. Revista de Teoría de la Literatura y Literatura Comparada, 32 (2019) Ellen Lambrechts

Poe, E. A. (1979): «Twice-Told Tales», en D. Galloway, ed., Selected Writings of Edgar Allan Poe. Poems, Tales, Essays and Reviews. Harmondsworth, Penguin books, pp. 437- 447.

Real ACADEMia EsPañola (2014): Diccionario de la lengua española, $23^{\mathrm{a}}$ ed. Madrid, Espasa.

REISZ, S. (2001): «Las ficciones fantásticas y sus relaciones con otros tipos ficcionales», en D. RoAS, ed., Teorías de lo fantástico. Madrid, Arco/Libros, pp. 193-221.

RoAs, D. (2001): «La amenaza de lo fantástico», en D. RoAs, ed., Teorías de lo fantástico. Madrid, Arco/Libros, pp. 7-44.

(2011): Tras los límites de lo real. Una definición de lo fantástico. Madrid, Páginas de Espuma.

RODRÍGUEZ HERNÁNDEZ, T. (2010): «La conspiración fantástica: una aproximación lingüísticocognitiva a la evolución del género», Espéculo. Revista de estudios literarios, núm. 43, pp. 1-11.

TODOROv, T. (1970) : Introduction à la littérature fantastique. Paris, Editions du Seuil.

TOuRY, G. (1978): «The Nature and Role of Norms in Literary Translation», en J. S. HolmES, J. LAMBERT y R. VAN DEN BROECK, eds., Literature and Translation. New Perspectives in Literary Studies. Leuven, Acco, pp. 83-100.

VeláZQueZ, R. (2012): «Procedimientos de irrupción de lo fantástico en Ajuar funerario, de Fernando Iwasaki», Cartaphilus. Revista de Investigación y Crítica Estética, núm. 10, pp. 178-194.

Zavala, L., comp. (1993): Teorías del cuento, I: Teorías de los cuentistas. México, UNAM. 